\title{
THE MERGE PROJECT: Impacts of Electric Vehicles on the Distribution System Steady-State Operation
}

\author{
F. J. Soares ${ }^{1}$, P. N. Pereira Barbeiro ${ }^{1}$, C. Gouveia ${ }^{1}$, P. M. Rocha Almeida ${ }^{1}$, C. Moreira ${ }^{1}$ and J. A. \\ Peças Lopes ${ }^{1}$ \\ ${ }^{I}$ INESC TEC - INESC Technology and Science (formerly INESC Porto) and FEUP - Faculty of Engineering, University of \\ Porto, Campus da FEUP, Rua Dr. Roberto Frias, 378, 4200 - 465, Porto, Portugal. \\ fsoares@inescporto.pt,cstg@inescporto.pt,pnpb@inescporto.pt,pedro.almeida@fe.up.pt,cmoreira@inescporto.pt, \\ jpl@fe.up.pt
}

Keywords: Charging Strategies, Critical Mass, Distribution Grid, Electric Vehicle, Steady-State Operation

\begin{abstract}
This paper describes the main results of the MERGE project relative to Electric Vehicle (EV) charging strategies and the impacts of EV integration on the steady-state grid operation. MERGE is a $€ 4.5 \mathrm{~m}$, collaborative research project supported by the European Commission's Seventh Framework Programme (FP7). The consortium includes utilities, regulators, commercial organisations and universities with interests in the power generation, automotive, electronic commerce and hybrid and electric vehicle sectors across the entire European Union (EU). One of the MERGE project missions is to evaluate the impacts that EV will have on EU electric power systems, exploring EV and SmartGrid/MicroGrid simultaneous deployment, together with renewable energy increase, to achieve $\mathrm{CO}_{2}$ emission reduction through the identification of enabling technologies and advanced control approaches. The work presented proposes three charging strategies, dumb charging, multiple price tariffs and smart charging, and uses EV integration scenarios of adherence to these charging schemes. The resulting scenarios are tested using an algorithm coded with Python and using PSS/E, created within the MERGE framework to study EU grids steady-state behaviour. Additionally, the critical mass of EV adherence to smart charging schemes that brings positive impacts to the distribution grids operation was also evaluated.
\end{abstract}

\section{INTRODUCTION}

The changes that the actual electric power systems are facing, namely in what regards renewables and Electric Vehicles (EV) integration, will require system operators to develop new network planning and operation strategies in order to deal with the new challenges arising from their large scale deployment. In what regards networks planning and operation, especially at the distribution level, the integration of EV should be seen not only as a challenge, but also as big opportunity to exploit the power systems' infrastructures in a more effective manner and to safely integrate larger quantities of renewables in the systems.

The large scale integration of EV is very likely to provoke several impacts in the power systems, namely at the distribution level, like changes in the branches loading, voltage profiles and load diagrams.
Since EV are expected to be plugged-in in the distribution systems, namely in Low Voltage (LV) and Medium Voltage (MV) grids, these type of networks are the ones where the EV charging impacts will be strongly noticed. Congestion problems are expected in already heavily loaded grids, while in radial networks voltage limits violations are likely to appear more frequently. The changes in the energy losses is also a matter of great concern, since the increase in the energy demand owed to EV charging will probably make their value rise considerably. The negative impacts referred are more prone to appear if uncontrolled EV charging strategies are used. In addition, the noncontrollability of the EV charging will also impact negatively the profit that the EV Supplier/Aggregators (EVSA) might achieve from the markets negotiations, as they will not have flexibility to shift the EV load towards the lower demand periods, being thus incapable of profiting from lower energy prices (Lopes et al., 2011). 
On the other hand, the possibility of controlling the EV charging will be of great benefit for both EVSA and Distribution System Operator (DSO). The EVSA will have the possibility of exploit the EV flexibility for charging, namely the EV that are parked during large periods of time overnight, thus profiting from lower energy prices. Under these circumstances, the EV charging management performed by the EVSA will naturally shift a significant amount of the EV load from the peak hours towards lower demand periods, contributing to improve the network operating conditions, to reduce the energy losses and to diminish the DSO need to invest in network reinforcements (Lopes et al., 2011)

Nevertheless, in order to develop adequate strategies to control the EV charging, it is first required to evaluate the impacts that this new elements will provoke in the power systems' operation.

The project MERGE (Mobile Energy Resources in Grids of Electricity) was created in order to seek for solutions for the aforementioned problems. Its mission is to evaluate the impacts that electric vehicles will have on the European Union (EU) electric power systems, in what regards planning, operation and market functioning. The focus is placed on EV and SmartGrid/MicroGrid simultaneous deployment, together with renewable energy increase, leading to $\mathrm{CO}_{2}$ emission reduction through the identification of enabling technologies and advanced control approaches (Bower et al., 2011).

One of the tasks of the MERGE project involved the development of an evaluation suite composed of several simulations tools capable of identifying the impacts that the EV integration will provoke in the electric power systems. The assessment has been performed by analysing several EU real networks using future EV integration scenarios for 2020 and 2030.

This paper presents the results obtained with one of the tools of the referred evaluation suite, which was developed to perform steady-state simulations in distribution networks (Rosa et al., 2011). The tool incorporates several EV models, allowing estimating the EV charging impacts in a given network, during a week period, when different charging strategies are adopted.

Five real MV networks were used as case studies. For each network it was calculated the maximum number of $\mathrm{EV}$ that can be safely integrated, the changes provoked by $\mathrm{EV}$ in the voltage profiles, lines loading, energy losses and in the load diagrams. A comparison between the results obtained for the maximum number of EV that can be safely integrated in the studied MV networks and the foreseen EV integration scenarios for 2020 and 2030 was also performed. Additionally, the critical mass (percentage) of EV owners that need to adhere to controlled charging schemes in order to enable the safe operation of the networks was also analysed.

A brief description of the methodology followed in the simulations, as well as the MV networks used as case studies, is presented in the next section.

\section{METHODOLOGY AND CASE STUDIES}

The methodology followed during the steady-state simulations can be divided in two parts: one to quantify the maximum EV number that can be safety integrated in a given network (section 2.1) and another to analyse the critical mass (section 2.3).

\subsection{Methodology to Quantify the Maximum Number of EV that can be Safely Integrated}

The quantification of the maximum number of EV that can be safety integrated in the distribution networks analysed was performed for each network considering three charging strategies: dumb charging, multiple tariff and smart charging.

In the dumb charging approach it is assumed that EV owners are completely free to connect and charge their vehicles whenever they want. The charging starts automatically in the moment when EV plug-in and only stops when the battery is fully charged or when the EV is disconnected from the grid by its owner. This approach should be described as a no control strategy but it is particularly important as it provides a measure for the assessment of the efficacy of the other management procedures.

The dual tariff intends to simulate a situation where electricity is cheaper during some specific hours of the day. For the simulations performed within the MERGE project, the cheaper period was assumed to be enclosed between $1 \mathrm{~h}$ and $7 \mathrm{~h}$.

The smart charging strategy envisions an active management system, where the EV aggregating entities are capable of managing the EV charging according to the market negotiations, always taking into account the EV owners' requests. In addition, it is assumed that the DSO is capable of monitoring all the elements connected to the grid and its state, having also the capability of interfering in the EV charging schedules in order to solve eventual technical problems that might appear in the grid. 
This type of management provides the most efficient usage of the resources available at each moment, enabling congestion prevention and voltage control.

During the simulations performed, the following EV charging scenarios were considered:

- All EV in dumb charging mode;

- All EV in multiple tariff mode;

- All EV in smart charging mode.

The implementation of the different EV charging strategies in the simulation platform is thoroughly described in (Rosa et al., 2011).

The simulations for each network and for each charging strategy starts assuming an EV integration that corresponds to a replacement of $1 \%$ of the conventional vehicles fleet by EV (see Table 1). The impacts of the referred EV integration level are then evaluated. If no violations of the network components' technical limits were detected, the EV integration percentage is increased by $1 \%$ and a new evaluation of the network operating conditions is performed in order to detect if any violation occurred. This process is repeated until one of the following conditions is verified: violation of the voltage limits specified and/or branch overloading.

The maximum percentages of EV that can be safely integrated in the MV networks analysed, for each charging strategy, is recorded in the end of the simulations.

In all the case studies, it was assumed the existence of one fast charging station per network. As it will be further demonstrated through the results presented in section 3, fast charging stations have a considerable impact in branches' congestion levels and in the voltage profiles. For this reason, the network bus to which the fast charging station was assumed to be connected, in each case study, was selected among the network buses with the highest voltage values. The EV resort to the fast charging stations when, during a journey, their battery SOC is not enough to complete the journey.

For the EV charging scenario that considers the multiple tariff, it was assumed that the period of lower energy prices is between $1 \mathrm{~h}$ and $7 \mathrm{~h}$, every day of the week.

\subsection{Networks Used as Case Studies}

As referred previously, a set of five real MV networks were used as case studies. These networks were carefully chosen in order to evaluate systems with different characteristics, like their topology (rural or urban) and their type of consumers (industrial, commercial or residential). In Table 1 it is presented the most relevant characteristics of the tested networks. A detailed description of these networks can be found in (Sánchez et al., 2010).

Table 1: Networks' characteristics.

\begin{tabular}{|c|c|c|c|c|c|}
\hline Network Name & $\begin{array}{c}\text { MV } \\
\text { Network } 1 \\
\end{array}$ & $\begin{array}{c}\text { MV } \\
\text { Network } 2 \\
\end{array}$ & $\begin{array}{c}\text { MV } \\
\text { Network } 3 \\
\end{array}$ & $\begin{array}{c}\text { MV } \\
\text { Network } 4 \\
\end{array}$ & $\begin{array}{c}\text { MV } \\
\text { Network } 5 \\
\end{array}$ \\
\hline Type of network & $\begin{array}{c}\text { Urban } \\
\text { network } \\
\text { from a } \\
\text { historic city } \\
\text { zone, } \\
\text { mainly with } \\
\text { commercial } \\
\text { consumers }\end{array}$ & $\begin{array}{c}\text { Rural } \\
\text { network }\end{array}$ & $\begin{array}{l}\text { Urban } \\
\text { network } \\
\text { from a } \\
\text { recently } \\
\text { built } \\
\text { residential } \\
\text { area in the } \\
\text { city centre }\end{array}$ & $\begin{array}{l}\text { Network from } \\
\text { a residential } \\
\text { area in the city } \\
\text { surroundings }\end{array}$ & $\begin{array}{c}\text { Network } \\
\text { from a } \\
\text { touristic } \\
\text { area }\end{array}$ \\
\hline Nr. of HV/MV substations & 9 & 5 & 18 & 8 & 8 \\
\hline $\begin{array}{l}\text { Voltage level } \\
\text { Nr. of buse }\end{array}$ & $\begin{array}{l}15 / 20 \\
930\end{array}$ & $13 / 13.2 / 20$ & $13.2 / 20$ & ${ }_{4598}^{20}-13-3$ & $\begin{array}{l}20 \\
15077\end{array}$ \\
\hline Nr. of branches & 1150 & 5355 & 2462 & 4680 & 15353 \\
\hline Peak power (MW) & 128.5 & 21.5 & 108.3 & 94.9 & 226.1 \\
\hline $\begin{array}{l}\text { Weekly energy } \\
\text { consumption (GWhi }\end{array}$ & 14.9 & 2.1 & 12.2 & 12.8 & 27.0 \\
\hline $\begin{array}{l}\text { Power factor of the } \\
\text { conventional load }\end{array}$ & 0.93 & 0.93 & 0.93 & 0.93 & 0.93 \\
\hline $\begin{array}{l}\text { Nr. of conventional } \\
\text { vehicles }\end{array}$ & 21135 & 5203 & 109641 & 21749 & 34155 \\
\hline $\begin{array}{l}\text { Bus where the fast } \\
\text { charging station is } \\
\text { installed }\end{array}$ & 25 & 4614 & 1419 & 31 & 12524 \\
\hline $\begin{array}{l}\text { Voltage lower limit (p.u.). } \\
\text { Period of lower energy }\end{array}$ & $\begin{array}{l}0.93 \\
1 \text { to } 7\end{array}$ & $\begin{array}{l}0.93 \\
1 \text { to } 7\end{array}$ & $\begin{array}{l}0.93 \\
1 \text { to } 7\end{array}$ & $\begin{array}{l}0.93 \\
1 \text { to } 7\end{array}$ & $\begin{array}{l}0.93 \\
1 \text { to } 7\end{array}$ \\
\hline
\end{tabular}

Besides the variables presented in Table 1, load diagrams may also have a significant influence in the results obtained. The load profiles of each network, during a typical week, are presented in Figure 1. As it can be seen, the load diagrams of the networks tested vary significantly. This variation may be explained by the different climate, socialcultural and economic conditions of each area. Despite de differences, well defined daily patterns are easily identified for all the networks except the rural, where the load consumption along the week is more irregular.

The identification of the daily load patterns is very important for the implementation of the dual tariff and the smart charging. For the former, the daily load patterns can be used to define the period during which the electricity price is lower, seeking to incentivize the EV owners to shift their EV existence charging to the lower demand periods. For the latter, the knowledge of daily load patterns will considerably ease the EVSA tasks in what regards the prediction of the EV load, since it will allow them to reduce forecasting errors and schedule the EV charging with higher accuracy.

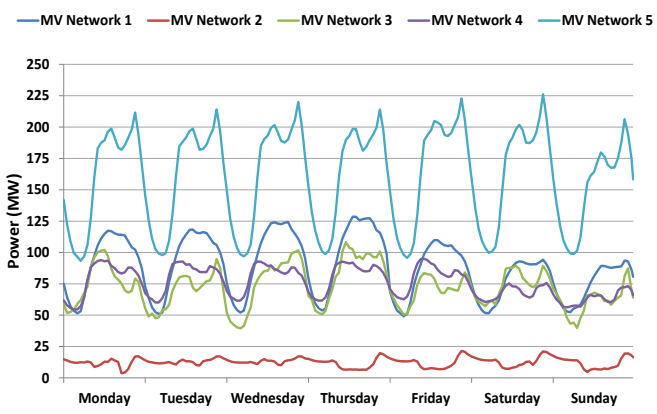

Figure 1: MV networks load profiles for a typical week. 


\subsection{Methodology and Case Study used in the Critical Mass Simulation}

For the critical mass study, the first step of the procedure followed consisted on the consideration of a fixed EV integration percentage, of which one half of the EV were assumed to be dumb charging adherents and the other half multiple tariff adherents. Then, if problems were not detected, the EV integration percentage was increased by $10 \%$, assuming the same proportion of dumb charging and multiple tariff adherents (50\% of each). This procedure was repeated until a problem in the network was detected (either a voltage lower limit violation or a branch overloading).

After detecting a technical problem, the second step of the procedure consisted on iteratively increasing the percentage of smart charging adherents, in steps of $5 \%$, while the dumb charging and multiple tariff adherents percentage was decreased accordingly, as explained in Figure 2.

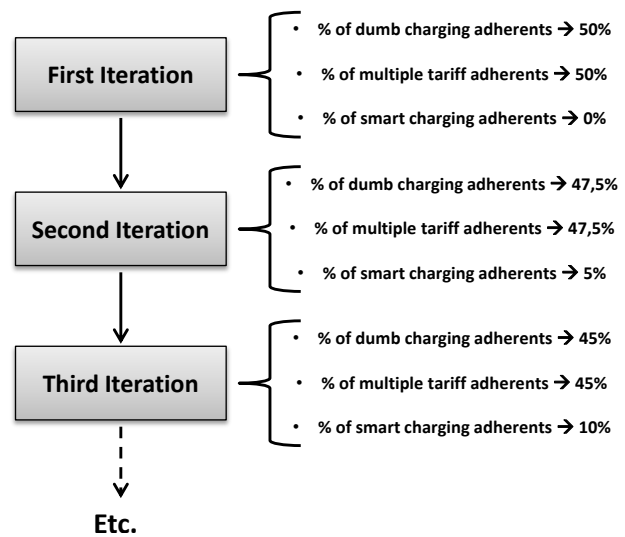

Figure 2: Flowchart of the steps followed for critical mass estimation

The second step of the procedure was repeated until the technical problems previously identified were solved. In the end of the procedure, the percentage of smart charging adherents that allowed solving the problems detected (the critical mass of smart charging adherents) was recorded.

The network used as case study for the critical mass simulation was the MV network 1 .

\section{RESULTS AND ANALYSIS}

\subsection{Changes in Load Diagrams}

The results presented in this subsection are referred to the maximum percentages of $\mathrm{EV}$ that can be safely integrated in the MV networks analysed, for each charging strategy, as well as to the changes in the weekly load diagrams verified. Due to space restrictions, only charts for one of the networks analysed will be presented (MV Network 1). However, the results presented in this section can be generalized for the remaining networks.

The maximum allowable EV integration percentages in the MV Network 1 are depicted in Figure 4 . The percentages are relative to the total number of conventional vehicles enclosed in the geographical area covered by this network, which was, in this case, 21135 vehicles. For the dumb charging, multiple tariff and smart charging, the number of EV that can be safely integrated in this network is, respectively, 5072, 7186 and 11836, which correspond to the percentages indicated in Figure 3 .

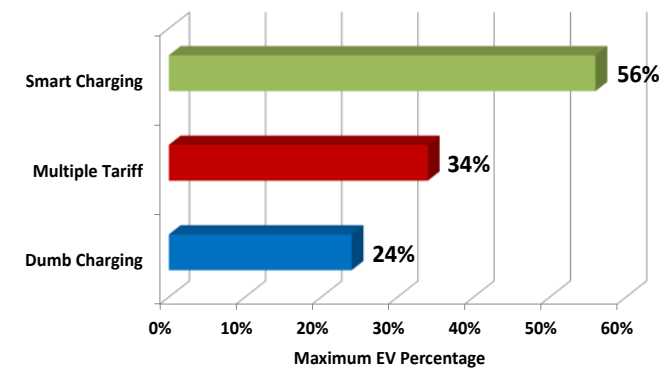

Figure 3: Maximum EV integration percentage in the MV Network 1 .

It is important to note that even when the smart charging is considered, the continuous load growth due to the increase of the EV integration provokes, at a certain moment, at least one technical constraint violation. In the case of the MV Network 1 , the first violation to occur was a branch overloading. The technical violations detected in the all the networks are presented in Table 4 and Table 5.

The EV power demand profile for the entire week, in MW Network 1, for the three charging strategies, is shown in Figure 4. When considering the dumb charging strategy, the EV tend to charge essentially at the end of the day, which is the time period when people arrive home from work. In the multiple tariff strategy, the EV owners tend to charge their vehicles between $1 \mathrm{~h}$ and $7 \mathrm{~h}$, which is the period of time when the energy prices are assumed to be lower. With the smart charging, the $\mathrm{EV}$ are charged mostly during the night, as this is the period when the EV availability is higher and the demand is lower. These two facts combined, make it possible to integrate a large number of $\mathrm{EV}$ in this grid without causing any technical constraints violations. 


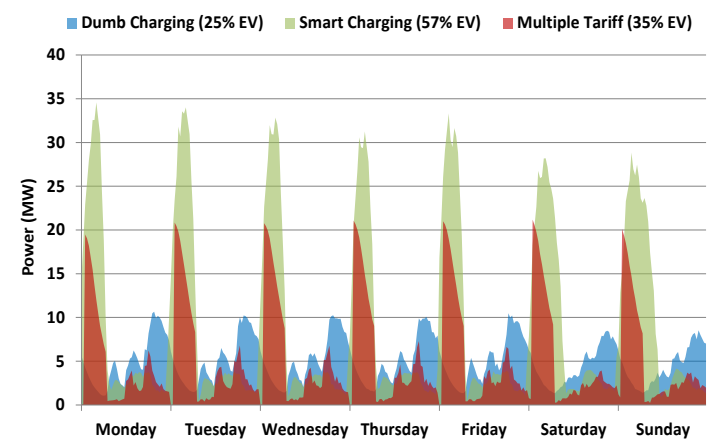

Figure 4: EV load demand profiles in the MV Network 1.

Adding the EV load depicted in Figure 4 to the conventional load of this network, makes it possible to compute the total load diagrams for the three charging strategies addressed, as presented in Figure 5. The load diagram for the scenario without EV reveals a relatively constant pattern during the week and the weekend days. A significantly large valley period is notorious during the nights, while during the days two small peaks are easily identifiable, one occurring during lunch time and the other during the evening.

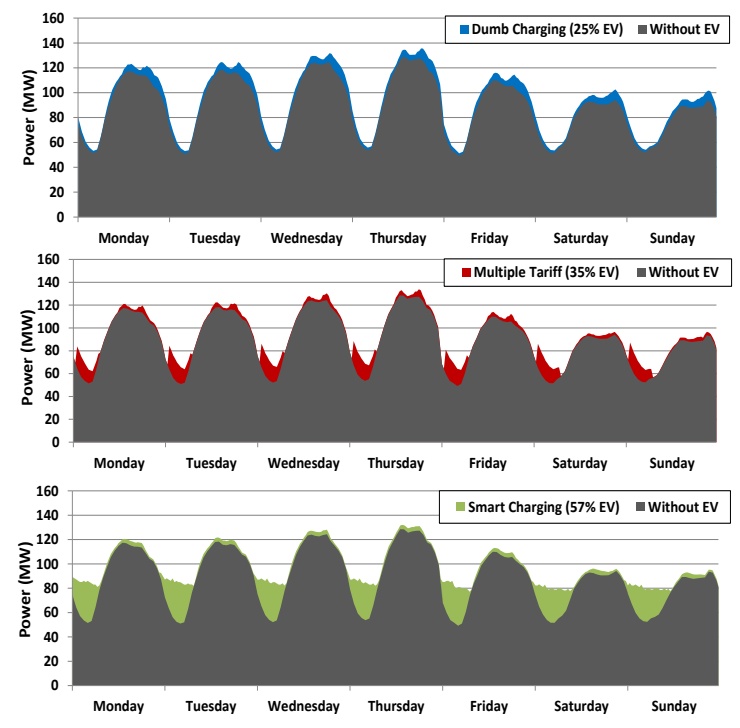

Figure 5: Load profiles without and with EV (MV Network 1).

In the scenario without $\mathrm{EV}$, this network has a peak load of $128.5 \mathrm{MW}$, which is incremented to 135.6 MW using the dumb charging, to 133.9 MW using the multiple tariff and to $132.1 \mathrm{MW}$ using the smart charging. The latter can be considered an outstanding achievement, since the peak load only increased 3.6 MW with an EV integration of $57 \%$, representing ca. $12047 \mathrm{EV}$.

It is interesting to notice that the EV charging, for the dumb charging and the multiple tariff, provokes changes in the hour at which the networks' peak load occurs. In the particular case of this network, the peak load occurrence changes from $14 \mathrm{~h}$ to $19 \mathrm{~h}$ of Thursday. For the smart charging, the hour at which the peak load occurs remains unchanged.

In Table 2 is presented an overview of the maximum EV integration percentage and the correspondent absolute value of EV allowed in each of the MV networks studied.

Table 2: Maximum EV allowed integration.

\begin{tabular}{|c|c|c|c|}
\cline { 2 - 4 } \multicolumn{1}{c|}{} & $\begin{array}{c}\text { Dumb } \\
\text { Charging }\end{array}$ & $\begin{array}{c}\text { Multiple } \\
\text { Tariff }\end{array}$ & $\begin{array}{c}\text { Smart } \\
\text { Charging }\end{array}$ \\
\hline MV Network 1 & $\begin{array}{c}24 \% \\
(5072 \mathrm{EV})\end{array}$ & $\begin{array}{c}34 \% \\
(7186 \mathrm{EV})\end{array}$ & $\begin{array}{c}56 \% \\
(11836 \mathrm{EV})\end{array}$ \\
\hline MV Network 2 & $\begin{array}{c}40 \% \\
(2081 \mathrm{EV})\end{array}$ & $\begin{array}{c}57 \% \\
(2965 \mathrm{EV})\end{array}$ & $\begin{array}{c}74 \% \\
(3850 \mathrm{EV})\end{array}$ \\
\hline MV Network 3 & $2 \%$ & $\begin{array}{c}4 \% \\
(2193 \mathrm{EV})\end{array}$ & $\begin{array}{c}8 \% \\
(87366 \mathrm{EV})\end{array}$ \\
\hline MV Network 4 & $\begin{array}{c}28 \% \\
(6090 \mathrm{EV})\end{array}$ & $\begin{array}{c}24 \% \\
(5220 \mathrm{EV})\end{array}$ & $\begin{array}{c}42 \% \\
(9135 \mathrm{EV})\end{array}$ \\
\hline MV Network 5 & $\begin{array}{c}10 \% \\
(3416 \mathrm{EV})\end{array}$ & $\begin{array}{c}5 \% \\
(1708 \mathrm{EV})\end{array}$ & $\begin{array}{c}24 \% \\
(8197 \mathrm{EV})\end{array}$ \\
\hline
\end{tabular}

From the results obtained, it can be observed that the analysed systems can handle, up to a certain level, the penetration of EV without concerns to the networks' infrastructures. However, it was verified that the maximum number of EV that can be safely integrated in the networks depends on the charging schemes adopted by the EV owners. From the three strategies analysed, smart charging yielded better results in all the case studies addressed, as with it was possible to reach higher EV integration levels without violating the networks' technical restrictions, meaning that higher investments deferral can be obtained. The dual tariff can be classified as the second best strategy, as in three of the five networks it attained better results than the dumb charging.

The fact of the dumb charging yielding better results than the multiple tariff in some of the networks can be explained by the instantaneous increase of the EV load verified around $1 \mathrm{~h}$ when the multiple tariff implemented. This occurs due to a large number of multiple tariff adherents starting their charging almost simultaneously. This load increase might occur in specific locations of the grid, where some grid components are already operating very near their limits, provoking the occurrence of technical violations. 


\subsection{Feasibility of the Foreseen EV Integration Scenario for 2020 and 2030}

The purpose of this section is to evaluate the feasibility of the foreseen EV integration scenarios for 2020 and 2030, which were defined by the MERGE partners in (Hasset et al., 2011).

In the referred deliverable of the project, three possible EV penetration scenarios for the period between 2010 and 2030 were defined. From the three scenarios defined, the one recommended to be used as reference by the MERGE partners was scenario 2 , as it is in-between a rather pessimistic scenario and the most optimistic one. Following this recommendation, and taking into account that the networks analysed are Spanish, the values obtained in scenario 2 for Spain were selected to be used as comparison basis for the results presented in this section.

The feasibility of the EV integration levels defined for the years 2020 and 2030 was evaluated as follows:

1) It was calculated the total number of EV that are expected to be integrated in each of the MV networks analysed, for 2020 and 2030. These values were computed assuming that the number of EV present in each network is proportional to the number of conventional vehicles enclosed in the networks' geographical area.

2) Then, it was calculated the maximum number of EV that can be safely integrated in the analysed networks, with the different charging strategies (as presented and discussed in section 3.1)

3) Finally, it was performed a comparison between the values obtained in steps 1) and 2). The EV integration level forecasted is assumed to be unfeasible if the values obtained in step 1) are higher than those obtained in step 2) and feasible otherwise.

All the results obtained are presented in Table 3. The feasibility of the integration levels forecasted by the MERGE partners, for each charging strategy, is indicated by a cross.

As it can be seen, the only networks that are not capable of coping with the EV integration levels forecasted are the MV Network 3 and the MV Network 5, for the year 2030, both due to branches' overloading problems. While the MV Network 5 only presents problems when the dumb charging is implemented, the MV Network 3 has some branches overloaded with both dumb charging and multiple tariff. The smart charging yields the best results, since with it all the EV integration levels forecasted are feasible.

Table 3: Feasibility of the foreseen EV integration scenario for 2020 and 2030 .

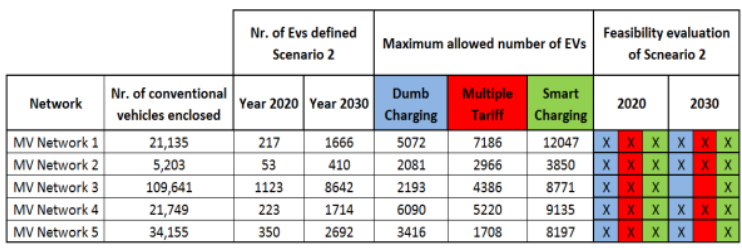

\subsection{Impacts in the Voltage Profiles}

Table 4 depicts, the voltage values obtained in the worst bus of the networks analysed, when the maximum allowable EV integration is reached. The values presented are referred to the hour at which the worst voltage conditions in the networks are verified, which can be different from the hour of the peak load.

Table 4: Voltage in the worst bus (p.u.).

\begin{tabular}{|c|c|c|c|c|}
\cline { 2 - 5 } \multicolumn{1}{c|}{} & $\begin{array}{c}\text { Without } \\
\text { EV }\end{array}$ & $\begin{array}{c}\text { Dumb } \\
\text { Charging }\end{array}$ & $\begin{array}{c}\text { Multiple } \\
\text { Tariff }\end{array}$ & $\begin{array}{c}\text { Smart } \\
\text { Charging }\end{array}$ \\
\hline $\begin{array}{c}\text { MV } \\
\text { Network 1 }\end{array}$ & $\begin{array}{c}1.0238 \\
(0 \% \mathrm{EV})\end{array}$ & $\begin{array}{c}1.0235 \\
(25 \% \mathrm{EV})\end{array}$ & $\begin{array}{c}1.0228 \\
(35 \% \mathrm{EV})\end{array}$ & $\begin{array}{c}1.0234 \\
(57 \% \mathrm{EV})\end{array}$ \\
\hline $\begin{array}{c}\text { MV } \\
\text { Network 2 }\end{array}$ & 0.9460 & 0.9295 & 0.9306 & 0.9310 \\
$(0 \% \mathrm{EV})$ & $(41 \% \mathrm{EV})$ & $(58 \% \mathrm{EV})$ & $(75 \% \mathrm{EV})$ \\
\hline $\begin{array}{c}\text { MV } \\
\text { Network 3 }\end{array}$ & 0.9721 & 0.9715 & 0.9721 & 0.9704 \\
$(0 \% \mathrm{EV})$ & $(3 \% \mathrm{EV})$ & $(5 \% \mathrm{EV})$ & $(9 \% \mathrm{EV})$ \\
\hline $\begin{array}{c}\text { MV } \\
\text { Network 4 }\end{array}$ & 0.9866 & 0.9853 & 0.9866 & 0.9848 \\
$(0 \% \mathrm{EV})$ & $(28 \% \mathrm{EV})$ & $(24 \% \mathrm{EV})$ & $(43 \% \mathrm{EV})$ \\
\hline $\begin{array}{c}\text { MV } \\
\text { Network 5 }\end{array}$ & 0.9722 & 0.9705 & 0.9722 & 0.9712 \\
$(0 \% \mathrm{EV})$ & $(10 \% \mathrm{EV})$ & $(5 \% \mathrm{EV})$ & $(24 \% \mathrm{EV})$ \\
\hline
\end{tabular}

As it can be observed, with the exception of the MV Network 2, the EV extra demand provokes almost insignificant voltage drops when comparing with the initial scenario (with no EV present in the grids). It is important to recall that in MV networks the $\mathrm{R} / \mathrm{X}$ ratio is low, contrarily to LV networks, what makes the impacts of the active power consumed by $\mathrm{EV}$ less relevant regarding voltage drops. In addition, as the majority of the MV networks studied are from urban areas, they are more prone to congestion problems than to undervoltage issues.

The voltage values attained for the MV Network 1, MV Network 3, MV Network 4 and MV Network 5 are within acceptable values, while for the MV Network 2 they reach values near or even below the minimum limit allowed (defined for these networks as 0.93 p.u.).

From these results, it is possible to conclude that the voltage lower limit is very likely the technical constraint that impedes a higher EV integration level in the MV Network 2. 
Although the voltage values regarding the use of different charging strategies are presented in the same table, for all the networks, it should be stressed that they are referred to different scenarios of EV integration. Thus, the only possible fact that can be concluded from the values presented is that the smart charging provides better results, as it is the charging strategy that allows safely integrating a larger number of $\mathrm{EV}$ in all the case studies evaluated.

\subsection{Impacts in the Branches Congestion Levels}

Differently to what was verified for the voltage profiles, branches' congestion levels were the most critical aspect in the generality of studied networks, with especially emphasis in the networks with urban characteristics. Looking at Table 5, where the rating percentage of the most congested branch of each network is presented, it is possible to observe the effects of the EV charging when the three different charging methods are applied. The maximum rating limit allowed was assumed to be $100 \%$.

The results obtained show, in all the networks, that the branches' load levels considerably worsen with the growth of the number of EV present in the grids. In fact, branches overloading is the factor that limits a further EV integration in the MV Network 1, MV Network 3, MV Network 4 and MV Network 5. The MV Network 2, besides having low voltage problems, also presents branches' overloading issues.

Likewise to the voltage profiles, the rating values presented in Table 5 for the different networks are referred to different scenarios of EV integration. Thus, the only possible fact that can be concluded is that the smart charging provides better results, as it is the charging strategy that allows safely integrating a larger number of EV in all the case studies evaluated. If it was considered a fixed number of $\mathrm{EV}$ in the grids, the worst rating percentage obtained with the smart charging would be significantly lower than the value obtained with the dumb charging and the multiple tariff.

The dumb charging strategy is the charging scheme that accounts for the worst results in the MV Network 1, MV Network 2 and MV Network 3, while multiple tariff strategy accounts for the worst results in the MV Network 4 and MV Network 5. As referred previously, the worst results of the multiple tariff obtained in the MV Network 4 and MV Network 5, in comparison with the dumb charging approach, might be explained by the instantaneous increase of the EV load verified when a large number of multiple tariff adherents start their charging, almost simultaneously, in the beginning of the lower electricity price period.

The location of the fast charging stations is also a very important variable in what regards branches' overloading, as the large amount of power absorbed by these facilities might overload the branches upstream. This problem has in fact occurred in the MV Network 1 and MV Network 5, where the branches overloading registered was due to $\mathrm{EV}$ charging in the fast charging stations. For this reason, it is advisable that the installation of a fast charging station is always preceded by a detailed impact study.

Table 5: Rating in the worst branch.

\begin{tabular}{|c|c|c|c|c|}
\cline { 2 - 5 } \multicolumn{1}{c|}{} & $\begin{array}{c}\text { Without } \\
\text { EV }\end{array}$ & $\begin{array}{c}\text { Dumb } \\
\text { Charging }\end{array}$ & $\begin{array}{c}\text { Multiple } \\
\text { Tariff }\end{array}$ & $\begin{array}{c}\text { Smart } \\
\text { Charging }\end{array}$ \\
\hline $\begin{array}{c}\text { MV } \\
\text { Network 1 }\end{array}$ & $\begin{array}{c}96.5 \% \\
(0 \% \mathrm{EV})\end{array}$ & $\begin{array}{c}100.0 \% \\
(25 \% \mathrm{EV})\end{array}$ & $\begin{array}{c}101.6 \% \\
(35 \% \mathrm{EV})\end{array}$ & $\begin{array}{c}100.4 \% \\
(57 \% \mathrm{EV})\end{array}$ \\
\hline $\begin{array}{c}\text { MV } \\
\text { Network 2 }\end{array}$ & $\begin{array}{c}84.8 \% \\
(0 \% \mathrm{EV})\end{array}$ & $\begin{array}{c}100.6 \% \\
(41 \% \mathrm{EV})\end{array}$ & $\begin{array}{c}101.1 \% \\
(58 \% \mathrm{EV})\end{array}$ & $\begin{array}{c}100.4 \% \\
(75 \% \mathrm{EV})\end{array}$ \\
\hline $\begin{array}{c}\text { MV } \\
\text { Network 3 }\end{array}$ & $97.9 \%$ & $101.7 \%$ & $101.0 \%$ & $101.3 \%$ \\
$(0 \% \mathrm{EV})$ & $(3 \% \mathrm{EV})$ & $(5 \% \mathrm{EV})$ & $(9 \% \mathrm{EV})$ \\
\hline $\begin{array}{c}\text { MV } \\
\text { Network 4 }\end{array}$ & $79.1 \%$ & $100.1 \%$ & $102.4 \%$ & $100.5 \%$ \\
\hline $\begin{array}{c}\text { MV } \\
\text { Network 5 }\end{array}$ & $97.7 \%$ & $100.5 \%$ & $105.1 \%$ & $100.5 \%$ \\
$(0 \% \mathrm{EV})$ & $(10 \% \mathrm{EV})$ & $(5 \% \mathrm{EV})$ & $(24 \% \mathrm{EV})$ \\
\hline
\end{tabular}

\subsection{Energy Losses}

The weekly energy losses in the networks analysed, for all the scenarios studied, are presented in Table 6 . The first value presented in each cell is referred to the absolute value of the losses, while the second is relative to the ratio between the losses and the overall energy consumption in the networks.

Table 6: Weekly energy losses (MWh) and Losses/Total Energy (\%).

\begin{tabular}{|c|c|c|c|c|}
\cline { 2 - 5 } \multicolumn{1}{c|}{} & $\begin{array}{c}\text { Without } \\
\text { EV }\end{array}$ & $\begin{array}{c}\text { Dumb } \\
\text { Charging }\end{array}$ & $\begin{array}{c}\text { Multiple } \\
\text { Tariff }\end{array}$ & $\begin{array}{c}\text { Smart } \\
\text { Charging }\end{array}$ \\
\hline MV & $50.0 \mathrm{MWh}$ & $54.0 \mathrm{MWh}$ & $53.1 \mathrm{MWh}$ & $54.7 \mathrm{MWh}$ \\
Network 1 & $0.34 \%$ & $0.34 \%$ & $0.34 \%$ & $0.33 \%$ \\
& $(0 \% \mathrm{EV})$ & $(25 \% \mathrm{EV})$ & $(35 \% \mathrm{EV})$ & $(57 \% \mathrm{EV})$ \\
\hline MV & $45.5 \mathrm{MWh}$ & $58.0 \mathrm{MWh}$ & $63.1 \mathrm{MWh}$ & $66.7 \mathrm{MWh}$ \\
Network 2 & $2.17 \%$ & $2.39 \%$ & $2.49 \%$ & $2.54 \%$ \\
& $(0 \% \mathrm{EV})$ & $(41 \% \mathrm{EV})$ & $(58 \% \mathrm{EV})$ & $(75 \% \mathrm{EV})$ \\
\hline \multirow{2}{*}{ MV } & $82.5 \mathrm{MWh}$ & $87.5 \mathrm{MWh}$ & $87.9 \mathrm{MWh}$ & $92.4 \mathrm{MWh}$ \\
Network 3 & $0.68 \%$ & $0.69 \%$ & $0.69 \%$ & $0.68 \%$ \\
& $(0 \% \mathrm{EV})$ & $(3 \% \mathrm{EV})$ & $(5 \% \mathrm{EV})$ & $(9 \% \mathrm{EV})$ \\
\hline MV & $50.6 \mathrm{MWh}$ & $54.3 \mathrm{MWh}$ & $53.0 \mathrm{MWh}$ & $54.6 \mathrm{MWh}$ \\
Network 4 & $0.40 \%$ & $0.39 \%$ & $0.39 \%$ & $0.39 \%$ \\
& $(0 \% \mathrm{EV})$ & $(28 \% \mathrm{EV})$ & $(24 \% \mathrm{EV})$ & $(43 \% \mathrm{EV})$ \\
\hline \multirow{2}{*}{ MV } & $465.9 \mathrm{MWh}$ & $483.1 \mathrm{MWh}$ & $471.9 \mathrm{MWh}$ & $497.3 \mathrm{MWh}$ \\
Network 5 & $1.72 \%$ & $1.75 \%$ & $1.73 \%$ & $1.77 \%$ \\
& $(0 \% \mathrm{EV})$ & $(10 \% \mathrm{EV})$ & $(5 \% \mathrm{EV})$ & $(24 \% \mathrm{EV})$ \\
\hline
\end{tabular}

A significant increase in the absolute value of the weekly losses is easily identifiable when 
comparing the scenarios with and without EV. As the energy losses are directly proportional to the square of the current, when the demand increases, due to the EV charging, the current flowing along the grids' branches raises as well, provoking an increase in the losses.

Although the absolute value of the energy losses increases with the smart charging (due to a larger $\mathrm{EV}$ integration), its relative value reveals that this charging strategy is the one that yields best results in the majority of the cases studied.

The adoption of the multiple tariff strategy could also lead to some positive results. As it can be observed, when comparing this strategy with the dumb charging, it is possible to decrease losses relative value in four of the analysed networks (MV Network 1, MV Network 3, MV Network 4 and MV Network 5), mainly due to the load valleys in the load diagrams that occur between $1 \mathrm{~h}$ and $7 \mathrm{~h}$. The exception is the MV Network 2, where the valley hours occur in the late afternoon, not coinciding with the period when the majority of the multiple tariff adherents charge their EV: between $1 \mathrm{~h}$ and $7 \mathrm{~h}$.

Generally, the charging method that yields worst results is the dumb charging, since it leads to the occurrence of the highest peak loads, which, expectably, lead to the higher increases in the energy losses.

\subsection{Critical Mass Analysis}

The main goal of this study is to identify the percentage of EV owners that need to adhere to the smart charging in order to safely integrate a given number of EV.

The first step of the methodology implemented, as referred in section 2.3, consisted on the consideration of an initial EV integration percentage, of which one half of the EV were assumed to be dumb charging adherents and the other half multiple tariff adherents. Then, if problems were not detected in the network, the EV integration percentage was increased by 10 until a problem in the network was detected. For the MV Network 1, used as test case, the initial EV integration percentage assumed was of $10 \%$ and the first technical violation was detected with a $30 \% \mathrm{EV}$ integration.

The second step of the methodology consisted on iteratively increasing the percentage of smart charging adherents, in steps of 5\%, while decreasing the dumb charging and multiple tariff adherents accordingly. This procedure was repeated until the technical problems identified were solved. For the case study under analysis, the percentage of smart charging adherents that allowed solving the problems detected - the critical mass - was of $45 \%$.
The differences between both scenarios referred have a direct influence on the EV load profiles, as presented in Figure 6. In the first scenario (in blue), the EV power consumption has two daily peaks: one in the late afternoon (due to dumb charging adherents) and other during the first hours of the night (due to multiple tariff adherents). When the value of the smart charging adherents is incremented to $45 \%$, a decrease in $\mathrm{EV}$ power during the late afternoon peak can be noticed.

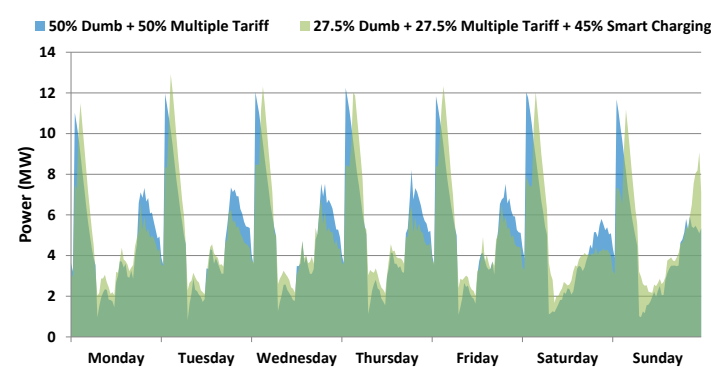

Figure 6: EV load demand profiles in the MV Network 1 $(30 \% \mathrm{EV})$

In Figure 7 are depicted the load diagrams for both cases studied. The peak load in the scenario with $45 \%$ of smart charging adherents slightly decreases, in comparison with the scenario with $50 \%$ dumb charging and 50\% multiple tariff.

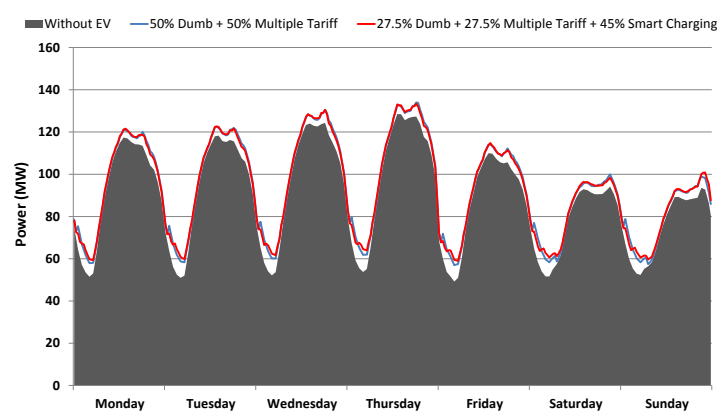

Figure 7: Load profiles without and with EV (MV Network 1,30\% EV)

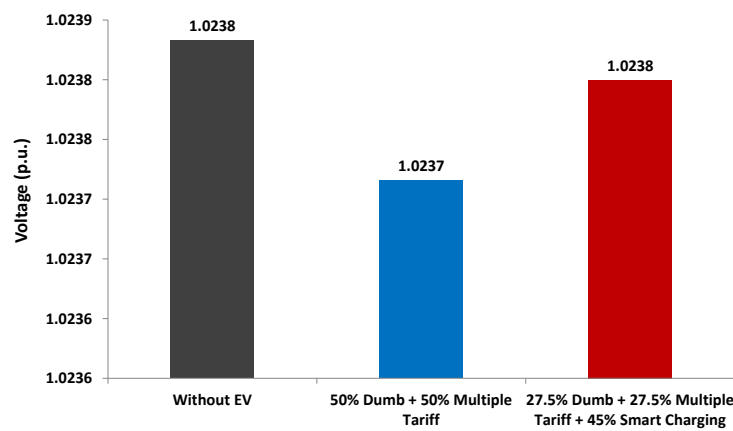

Figure 8: Voltage in the worst bus (30\% EV). 
Figure 8, Figure 9 and Figure 10 show, respectively, the voltages in the worst bus, the rating in the worst branch and the weekly energy losses for both scenarios simulated. As it can be noticed, the increase in the number of smart charging adherents yields benefits in all the indexes analysed.

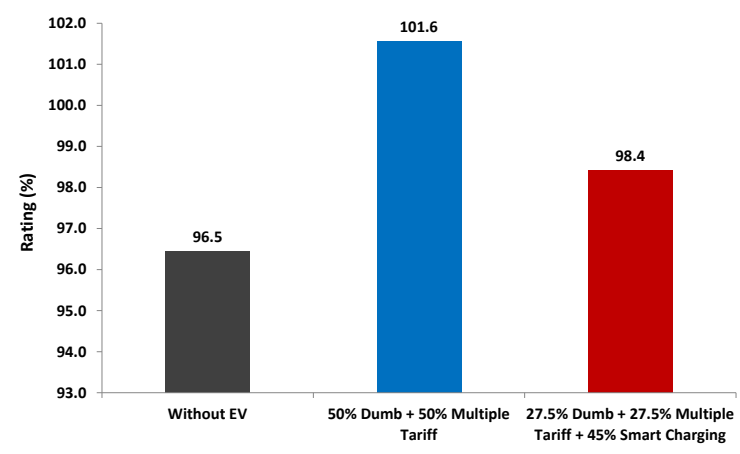

Figure 9: Rating in the worst branch (30\% EV).

As it can be seen in Figure 9, when considering $30 \%$ of $\mathrm{EV}$ integration, with $50 \%$ dumb charging and $50 \%$ multiple tariff, there are some branches already overloaded. The worst branch is $1.6 \%$ above its maximum rated capacity. By incrementing the share of smart charging adherents to $45 \%$ (critical mass value), while decreasing both dumb and multiple tariff adherents to $27.5 \%$, the worst branch rating decreases to $98.4 \%$, value within the allowed limits.

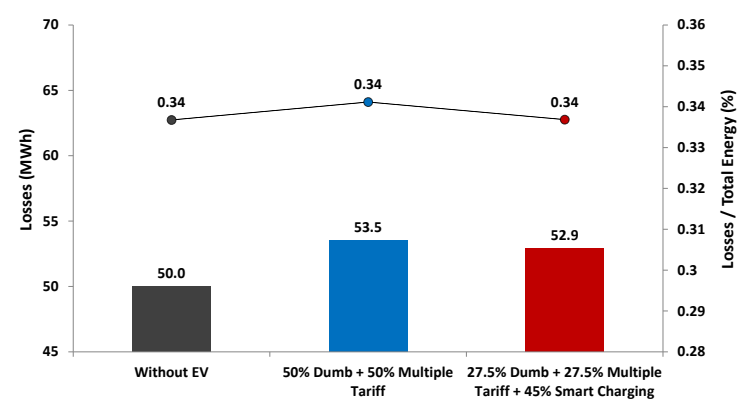

Figure 10: Weekly losses (30\% EV).

A rather obvious assumption about the critical mass is that its value is expected to increase as the number of EV connected to the grid raises. In order to prove it, a second scenario with a higher EV integration (40\%) was analysed. This EV integration level leads to a considerable aggravation of the branches congestion levels. The worst branch is ca. $10 \%$ above its maximum rated capacity, against the $1.6 \%$ verified in the previous case (with $30 \%$ of EV integration). Under these conditions, the worst branch rating can only be decreased to acceptable values if the smart charging adherents' percentage reaches $60 \%$ (critical mass value). As expected, this result proves that the critical mass increases as the $\mathrm{EV}$ integration level rises.

\section{CONCLUSIONS}

By analysing the results obtained from the steadystate simulations performed in the MERGE project, it was possible to verify that the magnitude of the EV impacts are influenced by several factors, like the EV integration level, the EV owners' behaviour, mobility patterns, the networks' load profiles and technical characteristics, the number and location of fast charging stations in the grid and the EV charging modes, among others. These factors have been carefully analysed, being possible to reach some important conclusions.

The analysed systems can handle, up to a certain level, the penetration of EV without concerns to the networks' infrastructures. However, it was verified that the maximum number of EV that can be safely integrated in the networks depends on the charging schemes adopted by the EV owners. From the three strategies analysed (dumb charging, dual tariff charging and smart charging), smart charging yielded better results in all the case studies addressed, since it was possible to reach higher EV integration levels without violating the networks' technical restrictions.

In what regards the EV impacts in networks with different topologies, some important conclusions were also attained. Concerning urban networks, as they are usually composed by short lines and are subjected to high power demand levels, they are very likely to face branch/transformer overloading problems faster than voltage drop issues. The results presented in this report prove this fact, as overload problems were identified in all networks studied with urban topologies. Differently from urban networks, rural networks have usually long radial lines, which provoke considerable voltage drops. Thus, low voltage problems are expected in these grids, namely in the buses farthest from the feeding points. The results obtained prove this fact, as low voltage problems were only detected in the rural network analysed.

The extra power demanded by EV also provokes several changes in the networks' load diagrams, which are more pronounced as the EV integration level rises. Nevertheless, the analysis performed allows concluding that it is impossible to generalise results in a rigorous manner, as the changes induced in the load diagrams depend of a large number of factors that are different from network to network. 
The location of the fast charging stations should be carefully analysed, as they might provoke severe voltage violations or branches overloading, due to the large amount of power that they may consume when in full operation. In fact, the studies performed have demonstrated that the overload problems identified in two of the studied networks were likely provoked by the power consumed in fast charging stations.

As it happened with the load diagrams, the simulations performed for the critical mass allow concluding that it is impossible to generalise results in a rigorous manner. From the analysis of the results obtained, it is only possible to conclude that the critical mass, besides being dependent of the network considered, increases with the EV integration level.

In what regards the feasibility of the forecasted EV integration scenario for 2020 and 2030, it was possible to conclude that, independently of the charging strategy adopted, no relevant problems in the MV networks are expected to occur until 2020. Conversely, in 2030, several problems are expected to arise, namely if dumb charging or dual tariff approaches are adopted. However, as results presented in section 3.2 show, the forecasted problems may be entirely solved if the smart charging is implemented on a large scale.

From the results obtained with the steady-state analysis performed within the MERGE project, it is clear that the path to safely integrate large quantities of $\mathrm{EV}$ in distribution networks, without making large investments in grid reinforcements, is to implement mechanisms that allow managing the EV charging not only taking into account their owners' requests, but also the networks' technical restrictions. Nevertheless, it should be remarked that the adherence to these controlled charging schemes will ultimately be always a decision of the EV owners. Thus, it is of utmost importance to timely define and implement adequate incentives' policies, attractive enough to make EV owners willing to participate in such controlled charging schemes.

\section{ACKNOWLEDGEMENTS}

This work was supported in part by Fundação para a Ciência e Tecnologia under Grants SFRH/BD/48491/2008 and SFRH/BD/47973/2008 and by the European Union within the framework of the European Project MERGE - Mobile Energy Resources in Grids of Electricity, Contract 241399 (7th Framework Programme).

\section{REFERENCES}

BOWER, E. T., LOPES, J. A. P., SOARES, F. J., RUA, D., HATZIARGYRIOU, N., STRUNZ, K. \& FERDOWSI, M. 2011. INITIAL FINDINGS OF 'MERGE' (MOBILE ENERGY RESOURCES IN GRIDS OF ELECTRICITY). JSAE EVTeC'11. Japan.

HASSET, B., BOWER, E. \& ALEXANDER, M. 2011. Evaluation of the impact that a progressive deployment of EV will provoke on electricity demand, steady state operation, market issues, generation schedules and on the volume of carbon emissions Deliverable D3.2 of the European Project MERGE.

LOPES, J. A. P., SOARES, F. J. \& ALMEIDA, P. M. R. 2011. Integration of Electric Vehicles in the Electric Power System. Proceedings of the IEEE, 99, 168-183.

ROSA, M., ISSICABA, D., GIL, N., SOARES, F. J., ALMEIDA, P. M. R., MOREIRA, C. RIBEIRO, P., HELENO, M., FERREIRA, R. SUMAILI, J., MEIRINHOS, J., SECA, L., LOPES, J. A. P., MATOS, M., SOULTANIS, N., ANESTIS, A., KARFOPOULOS, E., MU, Y., WU, J., EKANAYAKE, J. \& NARAYANA, M. 2011. Functional Specification for Tools to Assess Steady State and Dynamic Behaviour Impacts, Impact on Electricity Markets and Impact of High Penetration of EV on the Reserve Levels. Deliverable D2.2 of the European Project MERGE, .

SÁNCHEZ, C., GONZALEZ, A., ROSA, M. FERREIRA, R., CABRAL, P., BATISTA, F., ISSICABA, D., GIL, N., MOREIRA, C., RIBEIRO, P., DIAZ-GUERRA, B., PAPADOPOULOS, P., GRAU, I., VOUMVOULAKIS, E., ZOUNTOURIDOU, E., KARFOPOULOS, E., BOURITHI, FERDOWSI, M. \& ABBASI, E. 2010. Scenarios for the evolution of generation system and transmission, distribution grid evolution requirements for different scenarios of EV penetration in different countries. Deliverable D3.1 of the European Project MERGE. 